\title{
The Modified Bentonite Performance in Adsorption Process of Organic and Inorganic Contaminants from Aqueous Phase*
}

\author{
Le Thanh Son $^{\dagger}$ \\ Faculty of Chemistry, Hanoi University of Science, \\ Vietnam, 334 Nguyen Trai, Thanh Xuan, Hanoi, Vietnam \\ Truong Dinh Duc \\ Faculty of Chemistry, Hanoi University of Science, Vietnam, \\ 334 Nguyen Trai, Thanh Xuan, Hanoi, Vietnam and \\ Vietnam National Economics University, Hanoi, Vietnam, \\ 207 Giai Phong, Hai Ba Trung, Hanoi, Vietnam \\ Nguyen Van Bang \\ Faculty of Chemistry, Pedagogy University of Hanoi, \\ Vietnam, Xuan Hoa, Phuc Yen, Vinh Phuc, Vietnam \\ Dao Duy Tung and Hoa Huu Thu \\ Faculty of Chemistry, Hanoi University of Science, \\ Vietnam, 334 Nguyen Trai, Thanh Xuan, Hanoi, Vietnam
}

(Received 16 December 2009; Accepted 5 May 2010; Published 27 December 2011)

\begin{abstract}
Bentonite from Dilinh (Lamdong province, Vietnam) was used for pillaring and organofunctionalization process in the present study. The pillaring agent was obtained through controlled hydrolysis of $\mathrm{AlCl}_{3} \cdot 6 \mathrm{H}_{2} \mathrm{O} / \mathrm{NaOH}$. Aluminium pillared clay (Al-PILC) was prepared by contacting of Aluminium pillaring agent and Na-montmorillonite (MONT-Na) aqueous suspension with different ratios. Then, Al-PICL was organofunctionalized with cetyltrimethylammonium bromide (CTAB). The obtained materials were characterized by XRD, IR, DTA-TGA, SEM, BET and ${ }^{27}$ Al-MAS-NMR methods. On the ${ }^{27}$ Al-MAS-NMR spectrography of Keggin ions and Al-PICL tetragonal Aluminium $\mathrm{AlO} 4$ and hexagonal Aluminiums $\mathrm{AlO}_{6}$ appears at 66.14 and 0 ppm, respectively. The increase in $d_{001}$ of basal spacing was as expected since the pillaring causes an expansion in the interlayer distance. SEM is used to probe the change in morphological features of MONT-Na and Al-PILC. The surface morphology of MONT-Na is different from that of Al-PILC. The MONT-Na appears as corn flake like crystals, revealing its extremely fine platy structure. After pillaring, clay has become more porous. This porous appearance probably occurs due to the pillars formed between the interfaces of clay sheets as a result of pillaring and the reduction in certain amorphous phase originally associated with the MONT-Na. IR spectrography improved the interaction between Al-PICL and CTAB. Their adsorption capacity was investigated with methyl orange, methylene blue and copper ion from aqueous solution controlled temperature $298 \pm 0.20 \mathrm{~K}$. The obtained results show that Al-PICL-CTAB is best to remove organic contaminants from aqueous solution and also good to treat the water contaminated copper ion before re-use. [DOI: 10.1380/ejssnt.2011.458]
\end{abstract}

Keywords: Bentonite; Adsorption; Contaminant

\section{INTRODUCTION}

Natural clay minerals are well known and familiar to environment. Because of their low cost, abundance in most continents of the world, high adsorption properties and potential for ion-exchange, they are strong candidates as adsorption materials [1-10]. There are several classes of clays such as 2:1 type clays: pyrophylite-talc, smectites (montmorillonite, hectorite, beidelite, saponite), vermiculite, mica; 1:1 type clays: kaolinite [12]. Bentonite is primarily a Na-Montmorillonite (2:1 layered silicate), that swells when contacting with water. The inner layer is composed of an octahedral sheet of the general form $\mathrm{M}(\mathrm{OH})_{6}$ (where $\mathrm{M}$ is typically $\mathrm{Al}^{3+}$ ), which is situated

\footnotetext{
* This paper was presented at the International Workshop on Advanced Materials and Nanotechnology 2009 (IWAMN2009), Hanoi University of Science, VNU, Hanoi, Vietnam, 24-25 November, 2009 $\dagger$ Corresponding author: sonlt@vnu.edu.vn
}

between two $\mathrm{SiO}_{4}$ tetrahedral sheets. The net negative surface charge on the clay causes by the substitution of $\mathrm{Al}^{3+}$ for $\mathrm{Si}^{4+}$ in the tetrahedral layer and of $\mathrm{Mg}^{2+}$ or $\mathrm{Fe}^{2+}$ for $\mathrm{Al}^{3+}$ in the octahedral layer. The exchangeable cations such as $\mathrm{H}^{+}, \mathrm{Na}^{+}, \mathrm{Ca}^{2+}$ or $\mathrm{Mg}^{2+}$ neutralize the charge imbalance on the layer surfaces of the clay. In aqueous phase, the intercalation of water molecules into the interlamellar space of montmorillonite results in expansion of the bentonite [11-13].

With the net negative surface charge on the clay, these materials are very effective to remove some heavy metal ions and cationic organic compounds from waste water [1-10, 14-16]. However, the adsorption of nonionic and anionic organic solutes from aqueous phase to bentonite is relatively weak because of the preferential attraction of polar water molecules to the polar mineral surfaces. Thus, bentonite materials were organofunctionalized with organic cations to improve their adsorption capacity. The organic cations most commonly used for this purpose have been quaternary ammonium ions containing alkyl or aryl 
chains without specific functional groups [17-22].

In this work, aluminium pillared montmorillonites were organofunctionalized with CTAB. Their adsorption capacity was investigated with copper ion, methylene blue and methyl orange from aqueous solution controlled temperature $298 \pm 0.20 \mathrm{~K}$.

\section{EXPERIMENTAL}

\section{A. Preparation of materials}

$\mathrm{AlCl}_{3} \cdot 6 \mathrm{H}_{2} \mathrm{O}, \mathrm{NaOH}, \mathrm{NaCl}$ and other chemicals were analytical grade and were used without further purification. The MONT-Na was obtained by washing the raw bentonite (Dilinh, Lamdong Province) several times, first with a $3 \mathrm{wt} \% \mathrm{NaCl}$ aqueous solution and then with distilled water.

Preparation of Aluminium-Pillared Clay (Al-PILC). The Al-PILC was prepared according to the method described by Zhu, et al. [23]. The pillaring solution was prepared by adding dropwise $0.2 \mathrm{M} \mathrm{NaOH}$ to $0.1 \mathrm{M} \mathrm{AlCl}_{3}$ by vigorous stirring to an $\mathrm{OH} / \mathrm{Al}$ ratio molar of 2.0. The pillaring solution containing aluminium was added dropwise under vigorous stirring to a $1.0 \mathrm{wt} \%$ MONT-Na suspension to a ratio of $\mathrm{Al} /$ bentonite increased to $x \mathrm{mmol}$ of $\mathrm{Al} /$ gram of bentonite ( $x$ Al-PICL with $x=2.5,5.0,7.5$ and 10.0). The slurry was aged for $48 \mathrm{~h}$ at room temperature and the pillared clay was separated by filtration and washed with distilled water until the supernatant was chloride free as indicated by the $\mathrm{AgNO}_{3}$ test. The solid was washed and dried at $60^{\circ} \mathrm{C}$ for $24 \mathrm{~h}$.

Preparation of Aluminium-Pillared Clay organofunctionalized by CTAB (Al-PILC-CTAB). The CTAB solution was added dropwise under stirring to a $0.5 \mathrm{wt} \% \mathrm{Al}-$ PILC suspension to a ratio of CTAB/bentonite was of 2.0 mmol of CTAB/gram of clay.

\section{B. Characterization}

The synthesized samples were characterized by X-ray diffraction patterns XRD (SIEMEN D5005), by the IR transmission measurements (Nicolet Magna IR 760) at the center for materials, faculty of chemistry, Hanoi University of Science and nitrogen adsorption isotherms for surface area determination and pore size distribution BET (ASAP 2000) at The Petrochemical and Catalytic Materials Center, Hanoi University of Polytechnics. SEM analyses were done using a JEOS JSM - 5410 LV scanning electron microscope. The present of the tetragonal and hexagonal aluminiums in the pillaring solution and Al-PICL were identified by ${ }^{27}$ Al-MAS-NMR (CMX 360, Sweden).

\section{Procedures for Water Treatment}

A combination of 0.50 gram of clay and $100 \mathrm{ml}$ of solution with an appropriate concentration of the organic and inorganic contaminants was combined in $250 \mathrm{ml}$ flasks
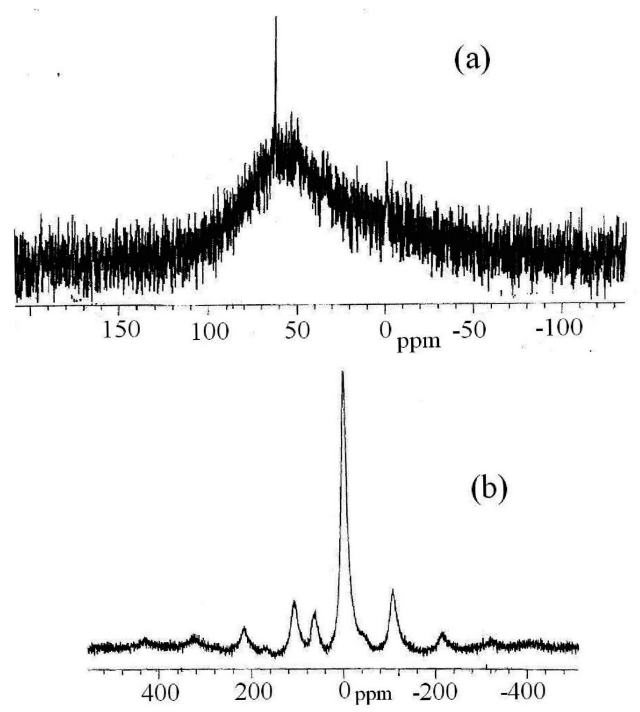

FIG. 1: ${ }^{27}$ Al-MAS-NMR spectrography of Keggin ions (a) and of Al-PICL (b), respectively.

with glass caps. After being filtered, the organic compound in the aqueous phase was determined by ultraviolet spectrophotometry and copper ion concentration was detected by atomic absorption spectrophotometric method. The losses of the compounds by both photochemical degradation and sorption to the flask in water treatment were found to be negligible. The aqueous solution was controlled temperature $298 \pm 0.20 \mathrm{~K}$.

\section{RESULTS AND DISCUSSION}

\section{A. Physicochemical characterization}

${ }^{27} \mathrm{Al}-\mathrm{NMR}$ spectroscopic data of ion Keggin and AlPICL (with the ratio of $5 \mathrm{mmol}$ of $\mathrm{Al} /$ gram clay) are shown in Fig. 1. Two signals were observed in spectra. The first signal at $0 \mathrm{ppm}$ is assigned to monomeric $\mathrm{Al}$ species $[24,25]$. The second signal at $66.14 \mathrm{ppm}$ attributed to $\mathrm{Al}$ atoms in fourfold coordination within a polymeric structure $\mathrm{Al}_{13}^{7+}$ complex [24, 26-28].

The bands of infrared spectra are listed in Table I. Bands at $3427-3469 \mathrm{~cm}^{-1}$ assigned to stretching vibrations of $-\mathrm{OH}[29]$. On the other hand, the characteristic IR bands of $\mathrm{Al}$ and $\mathrm{Mg}$ bound water molecule appear at $1634-1659 \mathrm{~cm}^{-1}$. The band at $1032-1035 \mathrm{~cm}^{-1}$ is assigned to the asymmetric stretching vibration of $\mathrm{Si}-\mathrm{O}-\mathrm{Si}$ of bentonite. Also the bands from 720 to $839 \mathrm{~cm}^{-1}$ are the most characteristic for quartz and the bands at $423-528$ can be attributed to typical $\mathrm{O}-\mathrm{Si}-\mathrm{O}$ bending vibrations [30].

After the Al-PICLs had been modified with CTAB, a pair of strong bands at 2843-2926 $\mathrm{cm}^{-1}$ and 1389-1482 $\mathrm{cm}^{-1}$ were observed which can be assigned to the symmetric and asymmetric stretching vibrations of the methylene groups $\left(-\mathrm{CH}_{2}-\right)$ and $(\mathrm{C}-\mathrm{N})$, respectively.

The properties of MONT-Na, organoclay, a series of $x$ Al-PICL and $x$ Al-PICL-CTAB (with $x=2.5,5.0,7.5$ and 10) were investigated by X-ray powder diffraction (XRD) analyses (see Fig. 2). The XRD analyses showed 
TABLE I: Bands in IR spectra, BET surface area and $d_{001}$ of materials obtained.

\begin{tabular}{|c|c|c|c|c|c|c|c|c|c|c|c|}
\hline \multirow[b]{2}{*}{ Materials } & \multicolumn{8}{|c|}{ Structure Group } & \multirow[b]{2}{*}{$\mathrm{C}-\mathrm{N}$} & \multirow[b]{2}{*}{$\begin{array}{l}\text { BET } \\
\text { surface } \\
\text { area } \\
\left(\mathrm{m}^{2} / g\right)\end{array}$} & \multirow[b]{2}{*}{$\begin{array}{l}d_{001} \\
(\mathrm{~nm})\end{array}$} \\
\hline & $\mathrm{H}-\mathrm{OH}$ & $\mathrm{OH}$ (str) & $\mathrm{Si}-\mathrm{O}$ & $\begin{array}{l}\mathrm{Si}-\mathrm{O}- \\
\mathrm{Al}^{0}\end{array}$ & $\begin{array}{l}\mathrm{Si}-\mathrm{O}- \\
\mathrm{Mg}^{0}\end{array}$ & $\mathrm{Al}^{0}-\mathrm{OH}$ & $\mathrm{Mg}^{0}-\mathrm{OH}$ & $-\mathrm{CH}_{2}-$ & & & \\
\hline MONT-Na & 3427 & 1639 & 1032 & - & - & 913.8 & 792.6 & - & - & 40.09 & 1.295 \\
\hline Organoclay & 3443 & 1634.1 & 1033.5 & 523.9 & 467.8 & 910.8 & 792.3 & - & - & - & 2.338 \\
\hline 2.5Al-PICL & 3444.2 & 1650 & 1034 & 525.5 & 469.6 & 910.8 & 792.3 & - & - & 118.71 & 1.825 \\
\hline $\begin{array}{l}2.5 \mathrm{Al}-\mathrm{PICL}- \\
\text { CTAB }\end{array}$ & 3445.7 & 1653.2 & 1035.4 & 526.2 & 469.6 & 910.8 & 796.1 & $\begin{array}{l}2926- \\
2843.6\end{array}$ & 1389.6 & - & 2.554 \\
\hline 5.0Al-PICL & 3421 & 1639 & 1034 & 527.5 & 468.6 & 918.5 & 792.6 & - & - & 184.32 & 1.910 \\
\hline $\begin{array}{l}\text { 5.0Al-PICL- } \\
\text { CTAB }\end{array}$ & 3448 & 1638 & 1033 & 527.7 & 468.8 & 919.0 & 792.7 & $\begin{array}{l}2924- \\
2852\end{array}$ & 1476 & - & 2.563 \\
\hline 7.5Al-PICL & 3443.8 & 1649.6 & 1035.1 & 525.4 & 469.4 & 919.0 & 796.4 & - & - & 203.3 & 1.913 \\
\hline $\begin{array}{l}\text { 7.5Al-PICL- } \\
\text { CTAB }\end{array}$ & 3447 & 1659 & 1035.0 & 525.0 & 470.0 & 910.2 & 797 & $\begin{array}{l}2920- \\
2852\end{array}$ & 1489 & - & 2.568 \\
\hline 10Al-PICL & 3469 & 1640.1 & 1035.1 & 528.2 & 469.1 & 910.8 & 755.5 & - & - & 167.57 & 1.912 \\
\hline $\begin{array}{l}\text { 10Al-PICL- } \\
\text { CTAB }\end{array}$ & 3444.5 & 1652.8 & 1035.1 & 525.5 & 468.2 & 919.0 & 792.3 & $\begin{array}{l}2923.3- \\
2851.8\end{array}$ & 1488.2 & - & 2.568 \\
\hline
\end{tabular}

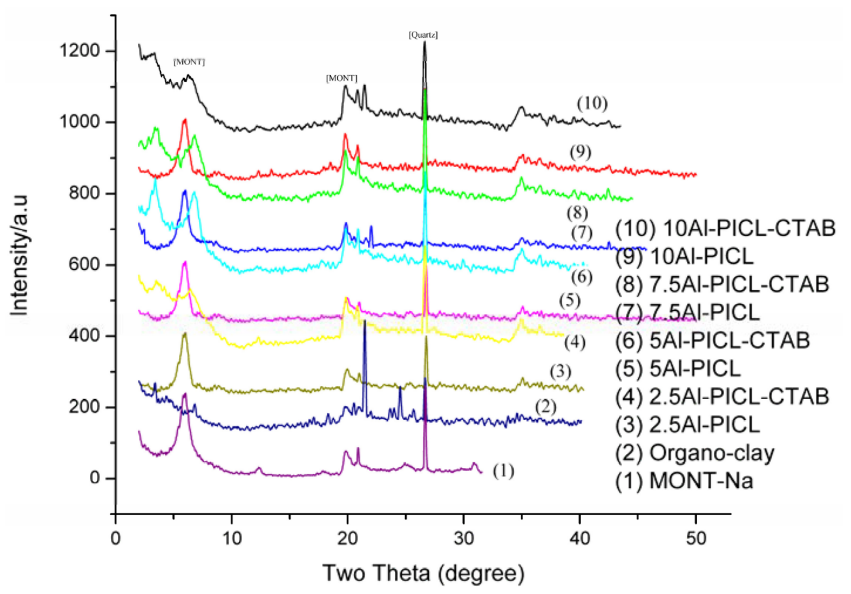

FIG. 2: Powder XRD patterns of MONT-Na, $x$ Al-PICL and $x$ Al-PICL-CTAB (with $x=2.5,5.0,7.5$ and 10.0).

that the interlayer spacing of MONT-Na is $1.295 \mathrm{~nm}$ with $75 \%$ relative humidity in the laboratory. The interlayer spacing of Al-PICLs increased gradually (see Table I). After modifying by CTAB, $d_{001}$ of Al-PICLs-CTAB are greater than of Al-PICLs (see Table I).

As shown in Table I, BET surface area of clay increases in pillaring by alluminium. BET surface area is largest if $x=7.5$ and then decreases if $x=10.0$.

\section{B. Adsorption process}

\section{Adsorption of copper ion}

Adsorption at a surface or interface is mainly a result of binding forces between the individual atoms, molecules or ions of the adsorbate and the surface, all of these forces originating in the electromagnetic interaction.

The metallic $\left(\mathrm{M}^{2+}\right)$ cations can be adsorbed on the available surface sites, represented by, $\equiv \mathrm{SOH}$, where $\mathrm{S}$ represents silicon or aluminium atoms in the inorganic structure, which are the main elements in the clay composition. For this process, the reactive edge sites on surface can interact with cations in solution, as represented by equations below: [31-33]:

$$
\begin{aligned}
\equiv \mathrm{SOH}+\mathrm{M}^{2+} & \rightleftharpoons \equiv \mathrm{SOM}^{+}+\mathrm{H}^{+}, \\
\equiv \mathrm{SOH}+\mathrm{M}^{2+}+\mathrm{H}_{2} \mathrm{O} & \rightleftharpoons \equiv \mathrm{SOMOH}+2 \mathrm{H}^{+}, \\
2 \equiv \mathrm{SOH}+\mathrm{M}^{2+} & \rightleftharpoons \equiv \mathrm{SO}_{2} \mathrm{M}+2 \mathrm{H}^{+} .
\end{aligned}
$$

On the surface sites, the original negative $\left(\equiv \mathrm{SO}^{-}\right.$) charge can exchange with cations $\left(\mathrm{M}^{2+}\right)$, as represented in equations below; $[34,35]$ :

$$
\begin{aligned}
2 \equiv \mathrm{SONa}+\mathrm{M}^{2+} & \rightleftharpoons \equiv \mathrm{SO}_{2} \mathrm{M}+2 \mathrm{Na}^{+} \\
\equiv \mathrm{SONa}+\mathrm{M}^{2+}+\mathrm{H}_{2} \mathrm{O} & \rightleftharpoons \mathrm{SOMOH}+\mathrm{Na}^{+}+\mathrm{H}^{+}
\end{aligned}
$$

Inner-sphere complexations are clearly more important than outer-sphere complexations for divalent metallic cations adsorbed by edge sites. Thus, the $\mathrm{pH}$ of the aqueous solution is an important controlling parameter in the adsorption process. In the present work, adsorption of copper ions on MONT-Na, $x$ Al-PICL and $x$ Al-PICL-CTAB adsorbents was studied over the $\mathrm{pH}$ range of 2.5-5.0 for constant adsorbent amounts of 1.0 g. $\mathrm{dm}^{-3}$ and concentration of cations of $520.0 \mathrm{ppm} . \mathrm{dm}^{-3}$ at $298 \pm 0.20 \mathrm{~K}$ (see Fig. 4). Adsorption increased almost linearly up to $\mathrm{pH} 5.0$ and both the extent of adsorption and the amount adsorbed showed a positive change. Adsorption experiments at $\mathrm{pH}$ values higher than 5.0 were not carried out because of the risk of copper cation in hydrolysis process.

As shown in Fig. 3, the amount adsorbed increased in the $\mathrm{pH}$ range with no observation of precipitation of copper hydroxide. This was in conformity with the results of a blank experiment without the presence of adsorbents. When the $\mathrm{pH}$ is lower than 6.0 , the $\mathrm{Cu}^{2+}$ adsorption amount is low and increases slowly with the $\mathrm{pH}$ 

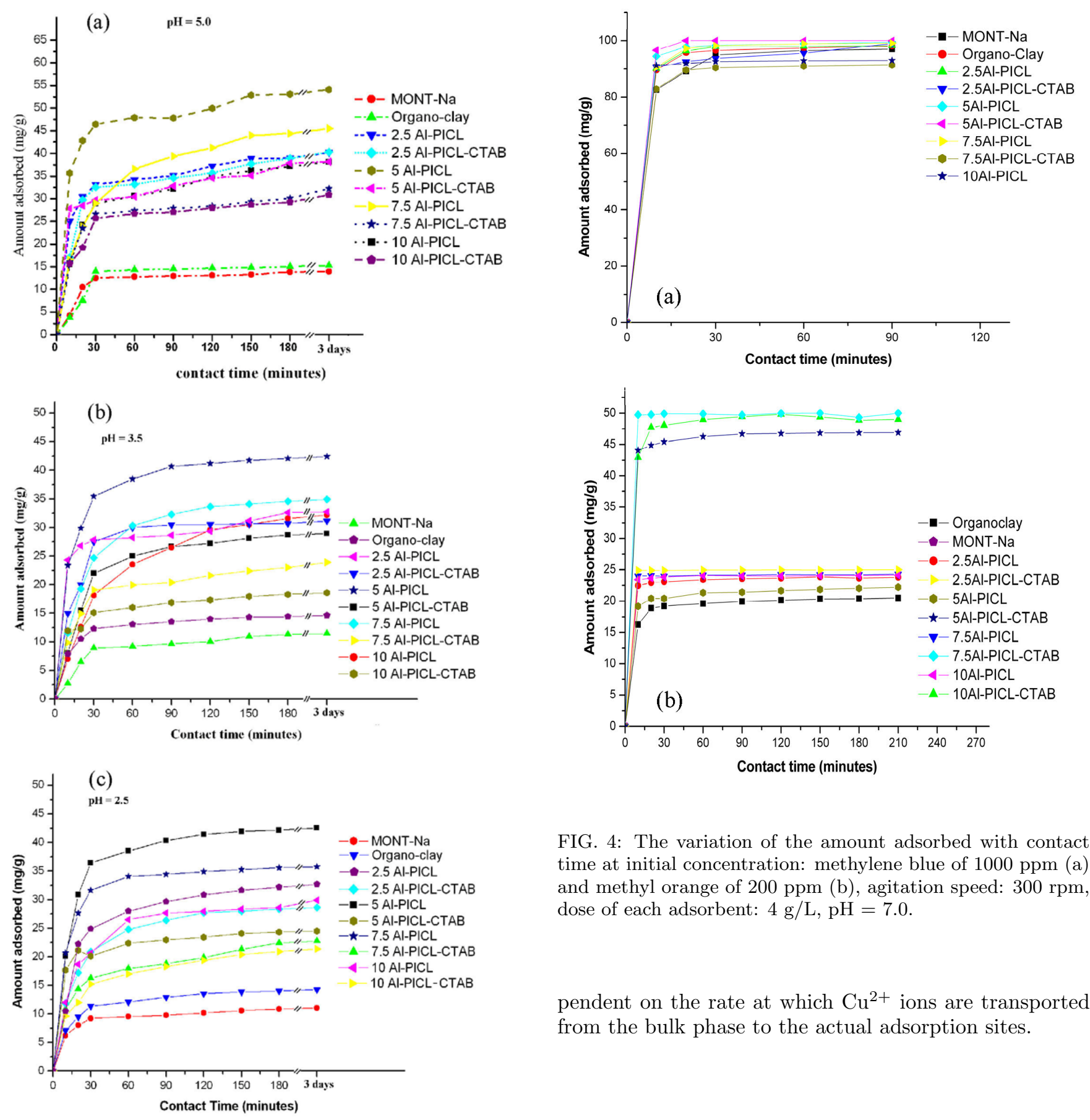

FIG. 4: The variation of the amount adsorbed with contact time at initial concentration: methylene blue of $1000 \mathrm{ppm}$ (a) and methyl orange of $200 \mathrm{ppm}(\mathrm{b})$, agitation speed: $300 \mathrm{rpm}$, dose of each adsorbent: $4 \mathrm{~g} / \mathrm{L}, \mathrm{pH}=7.0$.

pendent on the rate at which $\mathrm{Cu}^{2+}$ ions are transported from the bulk phase to the actual adsorption sites.

\section{Adsorption of methylene blue and methyl orange}

FIG. 3: Variation of amount of $\mathrm{Cu}^{2+}$ adsorbed per unit mass $\left(q_{e}\right)$ with time at different $\mathrm{pH}$.

increase. This could be concerned to the high concentration of $\mathrm{H}^{+}$ions, which exceeds that of $\mathrm{Cu}^{2+}$ by several times, so that the metallic ions can hardly compete with $\mathrm{H}^{+}$for the binding sites on the surface of the clays.

The uptake of $\mathrm{Cu}^{2+}$ was very fast in the first 30 minutes, and then it continued to slowly increase up to $36 \mathrm{~h}$, when equilibrium was reached (Fig. 4). The initial uptake of $\mathrm{Cu}^{2+}$ is very high, because of a large number of adsorption sites are available for adsorption. When the sites are gradually filled up, adsorption process becomes very slow and the adsorption kinetics becomes more de-

The adsorption behaviour of methylene blue (MB) and methyl orange (MO) onto materials obtained were investigated at $\mathrm{pH}$ 7.0. Because of net negative surface charge on the materials obtained, the adsorption capacity of MB obtained was very fast in the first 30 minutes with all materials. In other hand, to remove MO from aqueous solution, these materials were modified by CTAB to improve their adsorption capacity.

As modifying by CTAB, the adsorption capacity of $x$ AlPICL-CTAB (with $x=5,7.5$ and 10) increases very fast. The adsorption capacity of 7.5Al-PICL-CTAB and 10Al-PICL-CTAB were highest. The presence of pillars $\left(\mathrm{Al}_{2} \mathrm{O}_{3}\right)$ is perhaps the main cause of this phenomenon. The presence of CTAB affected weaker on the adsorption. 


\section{CONCLUSION}

This paper has attempted to search multi-functional adsorbents from locally available and effective materials to treat wastewater contaminated both heavy metallic ions and organic compounds such as cationic and anionic dyes. Physico-characteristics proved that materials obtained were suitable as desired. Their adsorption capacity was done both heavy metallic ions and organic compounds. From adsorption results, it was shown that Al-PICls-CTAB are best to remove cationic or anionic dyes from aqueous solution and also good to treat the water contaminated copper ions before re-use. Undoubt- edly, modified bentonites offer a lot of promising benefits for commercial purposes in the future. It has also been recommended that additional work is required to predict the performance of the adsorption processes for cationic or anionic dyes and heavy metallic cations from real industrial effluents.

\section{Acknowledgments}

The authors wish to thank Nafosted code 104.06.136.09 for financial support.
[1] A. M. F. Guimarães, V. S. T. Ciminelli, and W. L. Vasconcelos, Appl. Clay Sci. 42, 410 (2009).

[2] T. Vengris, R. Binkiene, and A. Sveikauskaite, Appl. Clay Sci. 18, 183 (2001).

[3] K. G. Bhattacharyya and S. S. Gupta, Adv. in Colloid and Interface Sci. 140, 114 (2008).

[4] M. Jiang, Q. Wang, X. Jin, and Z. Chen, J. Hazardous Mater. 170, 332 (2009).

[5] D. Malferrari, M. F. Brigatti, A. Laurora, S. Pini, and L. Medici, J. Hazardous Mater. 143, 73 (2007).

[6] Y. El Mouzdahir, A. Elmchaouri, R. Mahboub, A. Gil, and S. A. Korili, Desalination 250, 335 (2010).

[7] A. Sampieri, G. Fetter, P. Bosch, and S. Bulbulian, Langmuir 22, 385 (2006).

[8] D. M. Manohar, B. F. Noeline, and T. S. Anirudhan, Ind. Eng. Chem. Res. 44, 6676 (2005).

[9] P. Wu,W. Wu, S. Li, N. Xing, N. Zhu, P. Li, J. Wu, C. Yang, and Z. Dang, J. Hazardous Mater. 169, 824 (2009).

[10] M. Jiang, Q. Wang, X. Jin, and Z. Chen, J. Hazardous Mater. 170, 332 (2009).

[11] L. Zhu, X . Ren, and S. Yu, Environ. Sci. Technol. 32, 3374 (1998).

[12] T. Shichi and K. Takagi, J. Photochem Photobiol C: Photochem Rev. 1, 113 (2000).

[13] S. A. Boyd, M. M. Mortland, and C. T. Chiou, Soil Sci. Soc. Am. J. 52, 652 (1988).

[14] A. Gärses, Ç. Doğar, M. Yalçin, M. Açikyildiz, R. Bayrak, and S. Karaca, J. Hazardous Mater. B 131, 217 (2006).

[15] N. Miyamoto, R. Kawai, K. Kuroda, and M. Ogawa, Appl. Clay Sci. 16, 161 (2000).

[16] C. H. Weng and Y. F. Pan, J. Hazardous Mater. 144, 355 (2007).

[17] T. Undabeytia, S. Nir, T. Sánchez-Verdejo, J. Villaverde, C. Maqueda, and E. Morillo, Water Research 42, 1211 (2008).

[18] R. Zhu, T. Wang, F. Ge, W. Chen, and Z. You, J. Colloid and Interface Sci. 335, 77 (2009).
[19] R. Zhu, L. Zhu, J. Zhu, F. Ge, and T. Wang, J. Hazardous Mater. 168, 1590 (2009).

[20] U. F. Alkaram, A. A. Mukhlis, and A. H. Al-Dujaili, J. Hazardous Mater. 169, 324 (2009).

[21] A. Meleshyn, Langmuir 25, 6250 (2009).

[22] L. Shu-Zhen and W. Ping-Xiao, J. Hazardous Mater. 173, $62(2010)$.

[23] H. Y. Zhu, W. H. Gao, and E. P. Vasant, J. Colloid and Interface Sci. 171, 377 (1995).

[24] A. Schutz, W. E. E. Stone, G. Pongelet, and J. J. Fripiat, Clay Clay Minerals 35, 251 (1987).

[25] T. J. Pinnavaia, M.S. Tzou, S. D. L. Landau, and R. H. Raythatha, J. Mol. Catal. 27, 195 (1984).

[26] M. N. Timofeeva, M. E. Malyshev, V. N. Panchenko, A. N. Shmakov, A. G. Potapov, and M. S. Melgunov, Appl. Catal. B 95, 110 (2010).

[27] C. Feng, H. Tang, and D. Wang, Colloids Surf. A: Physicochem. Eng. Aspects 305, 76 (2007).

[28] M. N. Timofeeva, S. Ts. Khankhasaeva, Yu. A. Chesalov, S. V. Tsybulya, V. N. Panchenko, and E.Ts. Dashinamzhilova, Appl. Catal. B 88, 127 (2009).

[29] M. J. Wilson, Clay Mineralogy Spectroscopic and Determinative Methods (Chapman and Hall, U.K., 1994).

[30] C. V. Farmer, The Infrared Spectra of Minerals (Mineralogical Society, London, 1974).

[31] P. Cañizares, J. L. Valverde, M. R. Sun Kou, and C. B. Molina, Microporous Mesoporous Mater. 29, 267 (1999).

[32] N. Maes, I. Hielen, P. Cool, and E. F. Vansant, Appl. Clay Sci. 12, 43 (1997).

[33] D. L. Guerra, V. P. Lemos, R. S. Angélica, and C. Airoldi, Colloids and Surfaces A 322, 79 (2008).

[34] C. Volzone, Microporous Mesoporous Mater. 49, 197 (2001)

[35] M. Sychev, M. Rozwadowski, A. P. B. Sommen, V. H. J. Beer, and R. A. van Santen, Microporous Mesoporous Mater. 37, 187 (2000). 